\title{
ОЦЕНКА РЕАКЦИИ МУЖСКОГО ГАМЕТОФИТА ТОМАТА НА ДЕЙСТВИЕ ПАТОГЕНОВ ALTERNARIA SPP.
}

\author{
Салтанович Т.И., Анточ Л.П., Дончилэ А.Н. \\ Институт генетики, физиологии и защиты растений, e-mail:tatianasalt@ mail.ru
}

\begin{abstract}
Research objective: to identify tomato genotypes resistant to Alternaria on variability and symptoms of male gametophyte on selective backgrounds with cultural filtrate of pathogens Alternaria spp. A set of gamete breeding techniques and genetic-statistical analysis were used in the experiments. Some patterns of the variability and heritability of traits in the tomato male gametophyte have been identified on media with filtrates of pathogens. The differences in the resistance of pollen to the filtrate influence were established; the differentiation and selection of genotypes for further breeding were made. These studies can be used at different stages of the selection process.
\end{abstract}

Key words: tomato, pollen, pollen tubes, selection, variability, selection, resistance, pathogens.

\section{Введение}

В последние годы большинство сельскохозяйственных культур реализуют только 20-25\% общего генетического потенциала продуктивности, при этом уровень потерь в результате атак патогенных организмов составляет 12\%, из которых 83\% болезней вызывают грибные патогены [1]. В этой связи наличие толерантности к указанным факторам является необходимым условием реализации потенциальной продуктивности. Для оценки, дифференциации и последующего отбора генотипов, устойчивых к действию различных абиотических и биотических воздействий, в том числе и грибных патогенов, довольно активно и успешно используется вариабельность признаков мужского гаметофита. Реализация и эффективность таких исследований базируются на общности структурных генов гаметофита и спорофита, а также генетической разнокачественности пыльцы. Такая оценка позволяет еще на 
репродуктивных этапах выявлять и селектировать формы с различным уровнем устойчивости для их последующего вовлечения в селекционных процесс [2-4]. Выявление закономерностей отклика чувствительной генеративной сферы на воздействие различных факторов и расшифровка наблюдаемых эффектов представляют не только научный интерес, но и являются важным этапом оценки устойчивости генотипов в процессе реализации селекционных программ [5].

Для томата, как и для других культур, проблема выявления генотипов устойчивых к патогенам весьма актуальна ввиду недостаточной устойчивости большинства современных сортов. При этом, следует отметить особую роль фитопатогенных грибов, которые оказывают огромное влияние на генетическую структуру и численность растительных популяций. Альтернариоз является вторым по значению заболеванием томата в открытом грунте, который способен также вызвать ощутимые потери урожая в пленочных теплицах [6]. При изучении влияния токсинов A. alternata на гаметофитное и спорофитное поколения томата установлено, что процессы и механизмы, связанные с патогенезом и формированием устойчивости к болезням, происходят как в вегетативных, так и в генеративных тканях [7]. Перекрытие в экспрессии генов между спорофитным и гаметофитным уровнями растения позволило авторам рекомендовать использование пыльцы для дифференциации восприимчивых и устойчивых растений, а также для отбора толерантных и устойчивых к фитотоксинам и другим селективным агентам генотипов. Ряд исследователей на различных культурах получили положительные результаты по идентификации генетических источников устойчивости к грибным патогенам путем отбора микрогаметофитов [8-9].

Учитывая то, что в условиях Молдовы наиболее часто альтернариоз у томата вызывают такие представители как A.alternata и A.consortiale, цель исследований состояла в дифференциации генотипов томата по устойчивости к действию культуральных фильтратов этих патогенов на основе вариабельности признаков мужского гаметофита.

\section{Материал и методы}

Эксперименты проводили с набором внутривидовых гибридных комбинаций $\mathrm{F}_{1}$ томата, которые выращивали в полевых условиях по общепринятой для томатов методике до стадии цветения. Собранную пыльцу для проращивания высевали на 3 варианта искусственных питательных сред: контрольный и опытные, дополненные культуральными фильтратами (КФ) патогенов A.alternata или A.consortiale. Культивирование пыльцы осуществляли в термостате при оптимальной температуре $27^{\circ} \mathrm{C}$. Анализировали препараты под микроскопом, определяли жизнеспособность пыльцы и длину пыльцевых трубок, затем вычисляли устойчивость этих показателей. Статистическую обработку полученных результатов проводили с использованием пакетов программ Statgraphics v. 5.2 и Exel 2013.

\section{Результаты и обсуждение}

В результате проведенных исследований установлено, что действие КФ патогенов оказывал существенное влияние на изменение признаков мужского гаметофита. Анализ значений показателей в опытных вариантах показал, что средний уровень жизнеспособности пыльцы на среде с FC A.alternata составлял 19,7士1,85\%, в тоже время на среде с FC A.consortiale значения этого показателя были несколько выше и составляли $23,0 \pm 1,45 \%$. В условиях действия патогенов отмечено и формирование 
довольно коротких пыльцевых трубок, длина которых в среднем составляла $16,6 \pm 1,10$

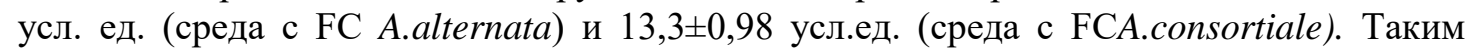
образом, у большинства генотипов отмечено снижение жизнеспособности пыльцы в опытных вариантах относительно контроля в $1.4 \ldots . .8 .3$ раза в зависимости от генотипа и культурального фильтрата. Вариабельность по длине пыльцевых трубок была наиболее существенной, в опытных вариантах в зависимости от гибрида значения этого показателя по отношению к контролю снизились в $4.5 \ldots .11 .2$ раз, что, вероятно, свидетельствует об их высокой чувствительности к дейстию патогена (рис.1).

Следует отметить, что в зависимости от генотипа выявленные изменения носили дифференцированный характер. Так, например, у гибрида $F_{1}$ VenetxElvira жизнеспособность пыльцы в опыте на среде с КФ A.consortiale была выше контрольных значений на $20.0 \%$, т.е. отмечен стимуляционный эффект, который может быть связан с повышенной устойчивостью пыльцы этого гибрида к действию патогена.

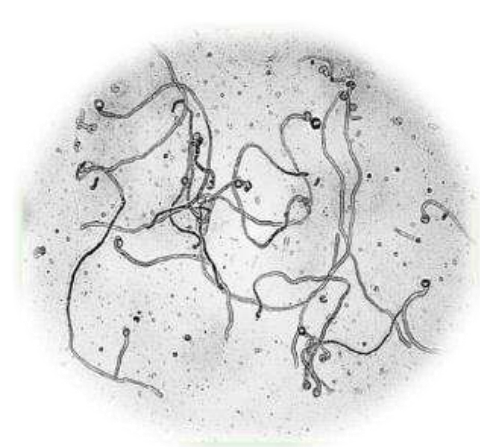

Контроль

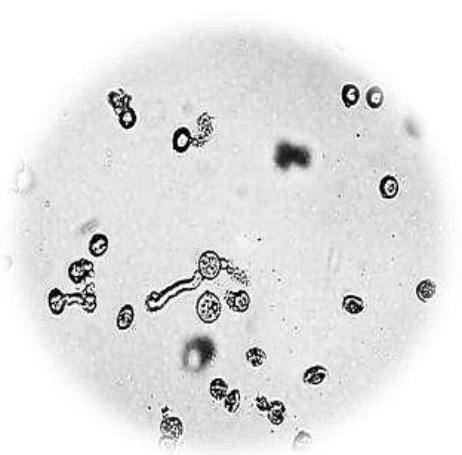

Среда с КФ A.alternata

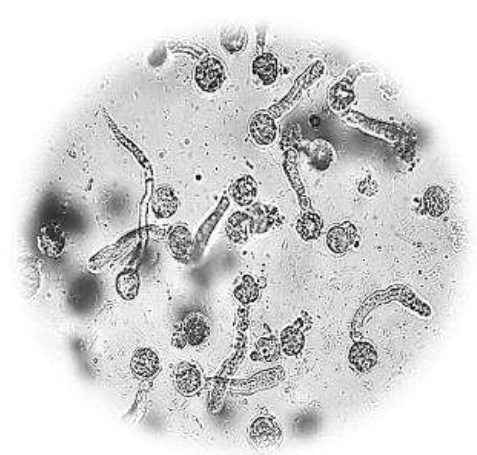

Среда $c$ КФ A.consortiale

Рис.1. Влияние культуральных фильтратов на изменение жизнеспособности пыльцы и длины пыльцеых трубок.

Для выявления основных источников изменчивости признаков мужского гаметофита проведена обработка полученных результатов методом многофакторного дисперсионного анализа. Установлено, что главным фактором, достоверно детерминирующим вариабельность изученных характеристик мужского гаметофита является культуральный фильтрат, сила его влияния в зависимости от варианта соствляет - $83,0 \ldots .93,2 \%(\mathrm{P} \leq 0,05)$, при этом роль генотипа и взаимодействие факторов также были достовеными, но гораздо более слабыми.

Известно, что для характеристики наследования признаков в $\mathrm{F}_{1}$ может использоваться степень доминантности. Полученные нами результаты по вычислению этого показателя показали, что из 44 возможных вариантов положительное доминирование отмечено в 30 случаях $(68,1 \%)$. Наиболее часто положительные значения степени доминантности выявлены для признаков устойчивость пыльцы к A.alternata и A. consortiale - 16 случаев (36,4\%). Одновременно по некоторым гибридным комбинациям отмечены промежуточные или отрицательные значения этого показателя (табл.1). 
Таблица 1. Степень доминантности $\left(\mathrm{h}_{\mathrm{p}}\right)$ признаков мужского гаметофита гибридов $\mathrm{F}_{1}$ томата

\begin{tabular}{|l|c|c|c|c|}
\hline \multirow{2}{*}{\multicolumn{1}{|c|}{ Гибриды }} & \multicolumn{4}{|c|}{ Степень доминантности, $\left(\mathrm{h}_{\mathrm{p}}\right)$} \\
\cline { 2 - 5 } & \multicolumn{2}{|c|}{ Устойчивость пыльцы } & \multicolumn{2}{c|}{ Устойчивость ПТ } \\
\cline { 2 - 5 } & A.alternata & A.consortiali & A.alternata & A.consortiali \\
\hline ElviraxMilenium & 0,30 & 67,7 & 8,65 & $-7,96$ \\
\hline ElviraxTomiș & 40,6 & 6,36 & 27,5 & 3,92 \\
\hline ElviraxPrestij & 8,97 & 51,6 & 2,2 & 3,24 \\
\hline MihaelaxMilenium & $-12,5$ & $-12,1$ & 6,45 & $-4,96$ \\
\hline MihaelaxTomiș & 31,6 & 26,6 & 6,58 & 3,87 \\
\hline MihaelaxPrestij & 3,5 & 2,58 & $-1,79$ & 26,6 \\
\hline JubiliarxMilenium & $-20,7$ & 16,8 & $-4,3$ & $-8,85$ \\
\hline JubiliarxTomiș & 13,24 & 0,34 & 21,9 & 30,8 \\
\hline JubiliarxPrestij & 6,3 & $-15,2$ & 3,11 & $-13,2$ \\
\hline MileniumxElvira & $-2,9$ & 8,94 & 15,5 & $-13,3$ \\
\hline MileniumxMihaela & $-7,5$ & 12,6 & $-0,8$ & 7,47 \\
\hline
\end{tabular}

Таким образом, как показали полученные результаты, для изученных гибридных комбинаций значения степени доминантности зависимы от особенностей генотипа, а также фона оценки устойчивости мужского гаметофита.

В результате проведенных экспериментов установлено, что между генотипами существуют значимые различия $(\mathrm{P} \leq 0,05)$ по показателям устойчивости мужского гаметофита.(рис 2).

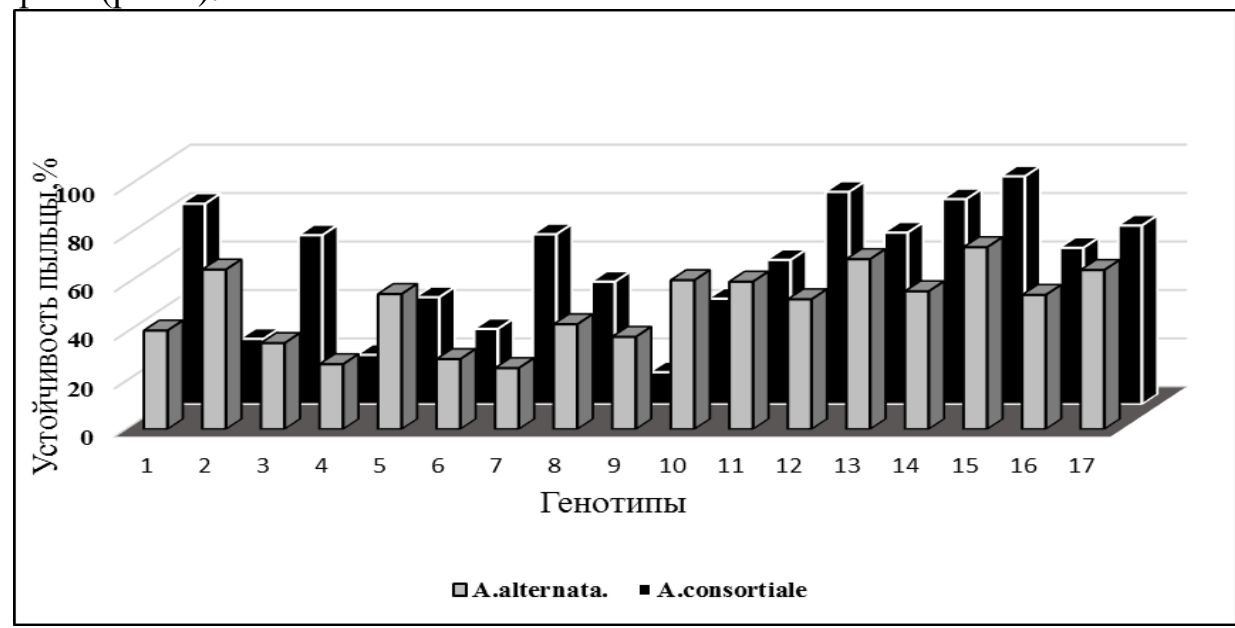

Рис.2. Устойчивость мужского гаметофита гибридов томата (1-17 - F 1 ElviraxMilenium, ElviraxTomiş, ElviraxPrestij, MihaelaxTomiş, MihaelaxPrestij, MihaelaxMilenium, JubiliarxMilenium, JubiliarxTomiş, JubiliarxPrestij, M.GratifulxTomiş, M.GratifulxPrestij, M.GratifulxJubiliar, M.GratifulxElvira, M.GratifulxMihaela, VenețxElvira, VenețxMihaela, VictorinaxMihaela).

В целом, следует отметить, что уровень устойчивости пыльцевых зерен на среде с КФ A.consortiale был более высоким и составлял в среднем 58,6\%, при этом в зависимости от генотипа признак изменялся от 13,2\% ( $\mathrm{F}_{1} \mathrm{JubiliarxPrestij)} \mathrm{до} \mathrm{94,4 \%}$ ( $\mathrm{F}_{1}$ VenetxElvira). В тоже время на среде с A.alternata значения этого показателя были 
ниже на 9,1\%, а в зависимости от генотипа признак варьировал от 25,0\% ( $\mathrm{F}_{1}$ JubiliarxMilenium) до 75,1\% ( $\mathrm{F}_{1}$ VenetxElvira). Обобщая полученные результаты, можем отметить, что более половины изученных генотипов проявили более высокую устойчивость пыльцы к действию КФ A.consortiale, тогда как только у 4-х гибридов гаметофит характризовался лучшей устойчивостью к КФ A.alternata, у 3-х гибридных комбинаций пыльцевые зерна сочетали примерно одинаковый уровень устойчивости к обоим КФ (рис.2Такие результаты, по нашему мнению, свидетельствуют о том, что действие КФ A.alternata оказывает более токсичный эффект и в результате существенее ухудшает качество пыльцы.

Таким образом, установлено, КФ Alternaria spp. существенно влияет на изменчивость признаков мужского гаметофита всех изученных генотипов томата. На фоне инфицирования питательных сред пыльцевые зерна гибридных комбинаций $\mathrm{F}_{1}$ томата качественно различаются по ряду изученных характеристик, в том числе и по устойчивости.

\section{Выводы}

В результате проведенных исследований выявлено дифференцированное действие КФ патогенов A.alternata и A.consortiale на вариабельность функциональных признаков мужского гаметофита гибридов томатов. Определены основные источники изменчивости и особенности наследуемости признаков мужского гаметофита на селективных питательных средах дополненных КФ патогенов. На основе неравноценности пыльцевых зерен показана возможность идентификации и отбора генотипов с разным уровнем устойчивости мужского гаметофита к альтернариозу, что может быть успешно использовано на различных этапах селекционного процесса.

\section{Библиография}

1. Petcu E., Ţerbea M, Lazăr C. Cercetări în domeniul fiziologiei plantelor de câmp la Fundulea. Fiziologia plantelor. Fundulea. v. LXXV. 2007. Volum omagial. p.431-459.

2. Бриль Е.А., Саук И.Б., Анохина В.С. Использование гаметофитного отбора для дифференцировки генотипов люпина по устойчивости к контрастным температурам. Материалы конф. Генетика и биотехнология в 21 веке. Фундаментальные и прикладные аспекты. Минск.2008. 51-53.

3. Кильчевский А.В., Антропенко Н.Ю., Пугачева И.Г. Изучение наследования урожайности и холодостойкости томата (Lycopersicon esculentum Mill). Весці Нацыянальнай Акадэміі навук Беларусі сер. агр. н. 4. 2007.68-74.

4. Georgios C. Koubouris, Ioannis T. et al. Impact of temperature on olive (Olea europaea L.) pollen performance in relation to relative humidity and genotype. Enviromental and Experimental Botany v.67, Issue 1, November 2009.209-214.

5. Ервандян, А. А. Небиш, Р. М. Арутюнян. С. Г. Использование морфологических показателей микрогаметофита для индикации загрязнения среды. Ученые записки Ереванского гос. Университета, Естств. науки, 1. 2009. 39-44.

6. Поликсенова, В. Д. Микозы томата: возбудители заболеваний, устойчивостъ растений. Минск: БГУ,2008.-159 с.

7. R. J. Bino, J. Franken, H. M. A. Witsenboer, J. Hille \& J. J. M. Dons Effects of A.alternata f.sp. Lycopersici toxins on pollen. Theoretical and Applied Genetics v. 76, 1988.204-208. 
8. Babu, D. Ratna; Ravikumar, R. L. Parallel response between gametophyte and sporophyte for Fusarium wilt resistance in the recombinant inbred lines of chickpea (Cicer arietinum L.). Current Science 2010, Vol. 99 Issue 4.513-518.

9. Shobha Rani T., Ravikumar R. Sporophytic and gametophytic recurrent selection for improvement of partial resistance to Alternaria leaf blight in sunflower (Helianthus annuus L.). Euphytica. 2006. 147: 421-443. 